\title{
New Research Methods of Sales-Marketing Interfaces
}

\section{G. HETÉNYI}

Debreceni Egyetem, Gazdaságtudományi Kar, Ihrig Károly Gazdálkodás- és Szervezéstudományok Doktori Iskola, gaborhetenyi@yahoo.com

Abstract: The energy invested in research in this topic is justified by the fact that the lack of optimal integration between SM (sales-marketing) can negatively affect overall corporate efficiency. The aim of this article is to present possible research methods that can reveal the impact of selected indicators, such as information exchange, coordination, vision and communication, conflicts, on the operation of the SM interface, according to Hungarian and foreign employees of international companies, and how they affect sales and marketing collaboration between pharmaceutical companies (PMC) and non-pharmaceutical companies (NPMC). It also attempts to demonstrate how the Partial Least Square (PLS) path modeling technique can provide valuable information on the consequences of management activity, and how the methods provided by Voyant Tools provide further research through quantitative analysis of qualitative data on the marketing sales interface (SMI), they can open up opportunities. The PLS-PM modeling technique was used to explore the relationships between the selected factors and possible hidden variables. These results clearly demonstrate that there are factors that influence SM collaboration that operate differently in PMCs and NPMCS, and that nationality differences can have a significant impact on how employees evaluate factors that affect SM collaboration. Of the methods we selected by Voyant Tools, the t-SNE (t-Distributed Stochastic Neighbour Embedding) tool proved to be the most sophisticated analysis, allowing the deepest analyzes by exploring relationships between groups of terms.

Keywords: sales-marketing interface, Voyant Tolls, cooperation, pharmaceutical industry, qualitative research

\section{Introduction}

Marketing and sales departments play a central role within companies and can be considered almost the only revenue-generating business. Due to the importance of this, it is in the interest of all companies that these functional areas work together in optimally coordinated strategies and in a coordinated manner. Future-oriented strategic coordination of these departments is essential for successful business management. Maintaining the competitiveness of firms also requires a strong operational implementation through the creation of concrete functional and instrumental measures. There can be a number of interface problems between marketing and sales, the failure of which to be addressed by management can make the work of both areas counterproductive, which can consequently negatively affect the success of the company (Haase, 2006). The performance of marketing and sales departments is highly dependent on the other class - reciprocal interdependence (Dewsnap \& Jobber, 2000) which may involve a number of conflict potentials. This can be the existence of unclearly defined roles and responsibilities, or even the lack of information exchange, common corporate goal, culture (Piercy, 2002). According to Lamasheva (2004), two important elements for optimal integration are the definition of the common goals of the parties and the results to be achieved. According to Klumpp 
(2000), due to interdependence, the separation of tasks is essential for coordinated collaboration. Therefore, there is a need for organizational mechanisms on the part of corporate management, such as the coordination of regular information exchange, which allows for the necessary coordination between the two departments, thus having a positive effect on the effectiveness of their relationship (Dawes et al., 2001). While there is a regular exchange of information, activities and resources are allocated, thus providing an opportunity to increase and complement each other's capacity to achieve multiple benefits and goals. However, all of this requires trust, commitment, and fairness between the two classes (Bititci et al., 2004). Preserving competitiveness is one of the goals to be achieved by enterprises, where cooperation and competition, or their intertwining, cooperation as a tool must be present (Raab, 2010).

According to Hackman and Oldham (1976), employee commitment and satisfaction is determined by three critical psychological factors: (1) the meaning of work: the employee's sense of how important and relevant the work he or she does is, (2) the individual's sense of responsibility for the outcome of the work: that the result of his efforts depends on his productivity, (3) knowledge of the value and consequences of work: how he performed his tasks (Gelei, 2005:163). Research suggests that the interpretation attributed to work in this way determines employee performance (Roberson, 1990; Shamir, 1991), and that the social environment in the workplace influences an individual's attitude and attitude to work (Salancik \& Pfeffer, 1978). This draws attention to the fact that establishing a relationship that is mostly confrontational is an important issue not only for the employee but also for the employer. It is important for companies primarily to retain employees, increase their commitment and motivation (Roberson, 1990), which paves the way for long-term cooperation, thus helping companies to remain competitive.

Cooperation is one of the most important strategic tools for development, the inspirations behind which can be very heterogeneous (Blomqvist et al., 2005). Unequal resource allocation can lead to confrontations (Bakacsi, 2001), which has been articulated in the literature as an perceived conflict of interest (Smith et al., 2004). Due to the existence of different goals, which may arise from the structure of the organization, there is a rather emphatic and manageable area of conflict, according to which the marketing and sales department have different concepts and approaches, so they do not have a specific definition of competencies (Vahs, 2012). While marketing has long-term, lasting and product-oriented ideas, sales have tendentious short-term and consumer-oriented ideas. These different perceptions then lead to the next state of whether the buyer or the product enjoys priority (Krafft, 1995).

Social identity and categorization, and the resulting distinction, are a very significant additional problem between the two classes that can be present as a psychic barrier, thereby inhibiting productive collaboration. In order to mitigate the negative effects of the resulting subcultures, it is necessary for the organizational units to get to know each other's working methods (Haase, 2006). According to literature data, the behavior of individuals is mostly regulated by subjective theories, subjective assumptions, and previously stored regulations. This can be developed through jointly organized corporate trainings and meetings, as well as job rotations (Dewsnap \& Jobber, 2000). The absence of the above-mentioned factors and the resulting interaction deficit develop a sense of competition instead of a constructive and progressive cooperation, which can lead to confusion, thus negatively contributing to the company's failure and a sense of mistrust (Wolfrum, 1994; Wunderer, 1985). 
The basic conditions for successful cooperation are the congruent common goal and the existence and proper communication of the designation of results (Lamasheva, 2004). This opens the door to a higherorder interaction that can create the conditions for dealing with joint tasks and uncertainties between the two departments (Miles et al., 2005), thereby directing the two parties to a more effective cooperation (Pinto et al., 1993).

In the course of work, not only the obligation itself is decisive, but also the consequence of the system of conditions and its activity (Genis \& Wallis, 2005). In terms of information conflict potentials, there is information exchange and communication between the two departments on the one hand, and the technical background required for this, on the other hand, arising from the Hard- and Software requirements (Wierum, 2001). In practice, the communication deficit can lead to marketing measures being implemented without taking sales information into account, and sales professionals are informed by customers about various promotions and activities within the company. Information exchange is particularly essential for strategic planning, especially in the early stages, where recognizing potential opportunities and threats is of paramount importance to the firm (Weber \& Schäffer, 2000). A further communication gap may be caused by a lack of compatibility / lack of technical background for the flow of information between departments (Cespedes, 1994). There is also a spatial separation of the two departments due to the differences in the areas of work performed, as sales people are mostly on the road, with marketers mostly doing office work (Bauer, 2000). All this negatively affects communication, which can be reduced by regular telephone and video conferencing and standardized communication methods. This interdependence holds several conflict potentials, where a detailed functional division promotes competition rather than integration between the two classes (Wunderer, 1985).

All in all, the cooperation of the two departments is an important element of corporate life, and as long as there is an optimal level of integration, the business will have a good chance of staying competitive. The relationship between these two interrelated departments is neither collaborative, nor harmonious, which can be due to multiple different reasons. The assessment of these factors serves as the focal point for my research. Therefore, my goal is to investigate and variously analyze these potential conflicts and to identify possible solutions that may play a fundamental role in the organization.

\section{Review of literature}

\subsection{Importance of integrating marketing and sales}

A close and clear relationship between the sales and marketing (SM) departments, especially their leaders is extremely important in the strategic development of the firm (Ahsan, 2018). Since both SM have turnover-related tasks, there will be interactions and interdependencies between them. It is these dependencies that make the cooperation of the two departments so interesting and rather instable (Haase, 2006; Dewsnap \& Jobber, 2002; Johnson, Matthes \& Friend, 2017). As research evidence demonstrates, the relationship of SM departments is not smoothly integrated in most companies (Homburg \& Jensen, 2007; Madhani, 2015). There are a number of interface issues between sales and marketing (Kotler et al., 2006; Malshe, Friend, Al-Khatib, Al-Habib \& Al-Torkistani, 2017b), which, if not resolved, will put the organisation at risk of making the work of both departments counterproductive 
and inefficient, thus negatively affecting the performance of the organisation (Haase, 2006; Moncrief, 2017).

Business activities are often characterised by optimisation - i.e. an attempt to achieve satisfaction rather than maximisation. In order to accomplish this, it is essential that in the decision making process the manager is in the know about capacity and strategy, and has previous experiences to build on (Cornaggia et al., 2017). In the operation of an organisation, innovation has a key role, which means a constant alertness to meet and satisfy customer needs by providing services. SM departments are amongst the key elements of the general algorithm of the innovation process. Examining this process along the innovation chain makes it clear that the starting point (marketing) and the end point (sales) of the chain is the market per se. Thus, taking the most relevant measures is the responsibility of the SM departments (Keszey \& Biemans, 2016). A smooth cooperation between these departments is largely affected by organisational and cultural corporate factors and it is crucial for the successful operation of the organisation - i.e. it serves as a foundation for a positive market response to the given product or service (Snyder et al., 2016).

In the business world, competition means monopolising value, whereas cooperation means a collective act of adding value (Snow, 2015). Lamasheva (2004) argues that the two elements that are essential for cooperation are common goals and clearly defined targets. Bargeron et al. (2015) stress the importance of trust between departments as well as dedication, fairness along with regular information exchange and a division of activities and resources in order to mutually enhance each other's capacities and maximise results. Staying competitive is one of the objectives of all enterprises, where competition and cooperation need to go hand-in-hand (Snow, 2015).

The relationship of the two departments has various interface challenges and conflicts which can be due to unclear roles and responsibilities as well as the lack of information exchange, common corporate goals or corporate culture (Razmerita et al., 2016). Klumpp (2000) believes that the cooperation between the two departments requires a division of tasks and the coordination of all relevant organisational mechanisms such as regular information exchange, which, in turn, will boost the effectiveness of their relationship by creating a permanent dialogue (Harmon, 2019). Discrepancies between SM can also be due to differences in their ways of implementing the corporate strategy, as marketing tends to focus on long-term strategic goals, whereas sales typically use sales techniques that generate short-term profit (West et al., 2015).

Another possible source of conflict might arise from the fact that different nationality employees might embrace different preferences and priorities concerning cooperation. The question of nationality as an influencing factor of corporate efficiency and interdepartmental cooperation has been examined earlier in various contexts (Rosenauer et al., 2016).

Out of all the processes contributing to profitability in companies, a smooth cooperation between these two departments is key (Krush, Malsche, Al-Khatib, Al.Jomaih \& Katoua, 2015). Thus, what management needs to do is build trust and efficient cooperation between these departments, relying on information and know-how from sales and incorporate it into strategic marketing decisions in order to promote product development and competitiveness. 


\subsection{Interfaces between marketing and sales}

The arising conflicts can be organisational (conflicting targets, incentives), personal (mindset, behavioral patterns) or informational (communication issues) (Cespedes, 1993, 1994; Rahim, 2017). Proper management of conflicts have a significant effect on the efficiency of pharmaceutical firms (Aljawazneh, 2015). Conflicts are often a result of the different perspectives of SM departments. Sales departments tend to set monthly or quarterly targets, whereas marketing usually has more long-term visions with no short-term sales commitments (Krafft, 1995; Rouziès et al., 2005; Malshe, Johnson \& Viio, 2017a). It is interesting to note that according to literature not all conflicts "are created equal", that is, conflicts, especially functional conflicts between the two departments can even be beneficial (Matsuo, 2006; Guenzi \& Troilo, 2007).

Potential information-related conflicts can be linked to communication and exchanging information between departments (Quirke, 2017; Thornton, 2019) on the one hand, and the necessary technical background, hardware and software requirements on the other (Wierum, 2001; Wang, Fang, Qureshi \& Janssen, 2015). Malshe et al. (2017) found empirical proof that SM communication paucity can seriously undermine trust between the two departments, which in turn, can have a strong negative effect on overall company performance.

Communication deficiencies can lead to a situation where marketing measures are implemented without taking sales aspects into consideration, or where sales staff get to know about company promotions and activities from their customers (Martinez \& Hurtado, 2018). Exchanging information is key to strategic planning, especially in the early stages where identifying potential opportunities and risks is crucial (Omar, Ramayah, Lo, Sang, \& Siron, 2010; Huang, Wu, Wen, Hsin-Fei \& Hairui, 2017). Further communication deficiencies can be caused by an incompatible/missing technical network between the departments (Järvinen \& Taiminen, 2016). Erturk and He (2018) analyse how a highly integrated CRM (Customer Relations Management) system can influence the mutually dependent operations of SM. Dalla Pozza, Goetz and Sahut (2018) point out that linking sales analysis with marketing segmentation through a well-functioning common CRM system can greatly help competitiveness. Pohludka and Štverková (2019) assess two years of experience with an online CRM platform and conclude that it has proved to be a robust system for both sales and marketing.

The following figure (see figure 1) represents a small selection of the reasons for the interface problem between marketing and sales.

From the marketing perspective

From the sales perspective

\begin{tabular}{|c|c|}
\hline $\begin{array}{c}\text { Sales people are not interested in corporate } \\
\text { branding, positioning and profitability, but only } \\
\text { in sales. }\end{array}$ & $\begin{array}{c}\text { In marketing, the focus is far too much on } \\
\text { internal processes. }\end{array}$ \\
\hline $\begin{array}{c}\text { Most in sales cannot interpret the marketing } \\
\text { plan, in addition sales support materials are } \\
\text { ignored by the sellers. }\end{array}$ & $\begin{array}{c}\text { The sales department does not receive any } \\
\text { support materials that they can use and if they } \\
\text { are, they are not suitable for the sales situation. }\end{array}$ \\
\hline
\end{tabular}




\begin{tabular}{|c|c|}
\hline $\begin{array}{c}\text { Information about needs and preferences will } \\
\text { not be passed on to marketing. }\end{array}$ & $\begin{array}{c}\text { The sales department, as just one executive } \\
\text { body, is only informed about upcoming } \\
\text { marketing campaigns. }\end{array}$ \\
\hline $\begin{array}{c}\text { Marketing arranges contacts at the trade fairs, } \\
\text { they are processed by sellers with whom they } \\
\text { get on well and who make little demands. }\end{array}$ & $\begin{array}{c}\text { The marketing people are sitting in an ivory } \\
\text { tower. They have no idea what our customers } \\
\text { actually want. }\end{array}$ \\
\hline $\begin{array}{c}\text { Marketing develops the strategy, sales should } \\
\text { implement it. Nevertheless, strategic corporate } \\
\text { goals are often ignored. }\end{array}$ & $\begin{array}{c}\text { Product managers design concepts far from any } \\
\text { reople make more money. }\end{array}$ \\
\hline Marketing people work hard and long, but sales
\end{tabular}

Figure 1: Reasons for the interface problem [own illustration, based on 23, 37]

Proper alignment and coordination of the SM is instrumental in ensuring a cost-efficient cooperation of the two departments (Kotler et al., 2006, Mayer \& Nyhuis, 2016). As Morgan and Slotegraaf (2012, p. 102) point out in connection with B2B firms marketing capabilities, ,... the development of different capabilities requires the coordination of various resources, skills and routines. The necessity of this form of coordination is also inevitable when it comes to harmonizing the relationship and interface interactions of SM departments within the company.

A strong and clearly communicated strategic corporate vision are further key elements of success (Tomek, Vávrová, Červenka, Naščáková and Tomčíková, 2016; Balmer, 2017). In an early empirical study, Baum, Locke, and Kirkpatrick (1998) found that a clear corporate vision has a positive effect on a company's overall performance only if it is clearly communicated to employees. The importance of effective internal communication was later confirmed by Ferdous (2008) and Martinez and Hurtado (2018).

According to Jo Hatch and Schultz (2002, p. 1047) strategic corporate vision is, „The central idea behind the company that embodies and expresses top management's aspiration for what the company will achieve in the future." A shared vision of SM departments can greatly enhance the effectiveness of cooperation between them (Madhani, 2016). In connection with pharmaceutical companies Birkinshaw, Zimmermann \& Raisch (2016) highlight the importance, a strong strategic vision plays in the adaptation capabilities of pharmaceutical manufacturing companies (PMC) analysing the example of GlaxoSmithKline.

According to Lamasheva (2004), common goals and their definition are an essential element of coordination and should be part of the life of every company in order to maintain competitiveness and ensure cooperation. The existence of a corporate culture and proper communication as management measures promotes teamwork and reduces conflicts (Song, Xie \& Dryer, 2000).

One way to improve the quality of communication gaps and cooperation between SM is to establish regular meetings and joint training programs for staff in the two departments. Kahn (1996) established the importance of cross-functional training for SM and later confirmed it by Le Meunier-FitzHugh and Piercy (2007). Matthyssens and Johnston point to the fact that "Joint training and development programs also stimulate the interface. A common jargon and thinking pattern is provided and the 
residential atmosphere of seminars leads to open discussions under professional guidance." (Matthyssens \& Johnston, 2006, p. 344). Kotler et al. (2006) developed a rating scale measuring instrument to tap into the relationship of SM. In their scale one item to be rated is, "Sales and Marketing jointly develop and deploy training programs, events, and learning opportunities for their respective staffs." (Kotler, Rackham \& Krishnaswamy, 2006, p. 6). In their study they also underline the importance of organizing regular common meetings for SM employees.

Data in the literature have confirmed that sharing and clarifying common goals can improve collaboration between the two departments (Kahn 1996; Le Meunier-FitzHugh and Lane, 2013). In assessing the determinants of MS integration, Sleep, Lam, and Hulland conclude: "Creating common goals or encouraging clients to visit together can lower boundaries. In addition, managers can create cross-functional groups to enhance the sharing of information and resources between functions to further increase interdependence, which reduces the integration gap and ultimately improves business results. "(Sleep, Lam \& Hulland, 2018, p. 15).

When clarifying the division of tasks and responsibilities between SM, it is worthwhile to build on a wellfounded distinction between sales and marketing functions during the operation of the company (Homburg, Jensen, \& Krohmer, 2008; Homburg, Alavi, Rajab) \& Wieseke, 2017). Homburg et al. they point out that while "Salespeople are usually responsible for a group of customers in a sales area or a particular industry segment, while marketing managers are usually responsible for a particular product or brand offered by a company." (Homburg, Alavi, Rajab, \& Wieseke 2017, p. 16). “... a lack of cooperation can be caused by a lack of understanding of each other's roles, ambiguity of roles, poor communication, a culture of responsibility, poor coordination of different perspectives and activities and goals. (Le Meunier-FitzHugh and Piercy, 2007, p. 942).

\section{Research hypotheses/questions}

\subsection{Exploring nationality differences affecting the cooperation of SM}

Based on factors considered important for the harmonisation of SM cooperation in the literature I preselected variables 12 variables that can have a potentially significant impact on SM cooperation and formulated my research questions and hypotheses $(\mathrm{H})$ based on their hypothesized interactions.

The formulated research questions and hypotheses:

- Q1: How does information exhange affect SM cooperation?

- H1: The more regular and frequent information exchange between SM is, the more cooperation there is between the two departments.

- Q2: How does coordination and the definition of roles and responsibilities affect SM cooperation?

- H2: The better the SM coordination is (more frequent common meetings, training sessions, common goals) and the clearer roles and responsibilities are defined, the better the SM will be.

- Q3: How does corporate vision and its communication affect SM cooperation? 
- H3: The clearer the company's vision is defined and communicated, and the better the company's general communication is, the more efficient the SM cooperation will be.

- Q4: How does information exchange affect SM cooperation?

- H4: Information exchange in any shape or form has a positive and equal effect on the coordination of $S M$.

- Q5: Do information exchange, coordination and corporate vision have a combine effect on SM cooperation?

- H5: Information exchange, coordination and corporate vision as elements of the company's management culture also have a combined effect on the cooperation between SM.

- Q6: Which of the three elements in Q5 have the biggest impact on SM cooperation?

- H6: Of all aspects of management culture, coordination has the most significant role in improving cooperation.

- Q7: What impact do conflicts between SM have on SM cooperation?

- H7: The more frequently conflicts between the two departments occur, the less cooperation there will be between them, and conflicts have a direct negative effect on cooperation.

- Q8: How does corporate vision and its communication affect information exchange between SM?

- H8: The clearer the corporate vision is defined and communicated, and the better the company's general communication is, the better the information exchange between SM will be.

(Hetényi et al., 2019)

Figure 2 (see figure 2) summarizes the hypotheses and depicts the variables in blocks.

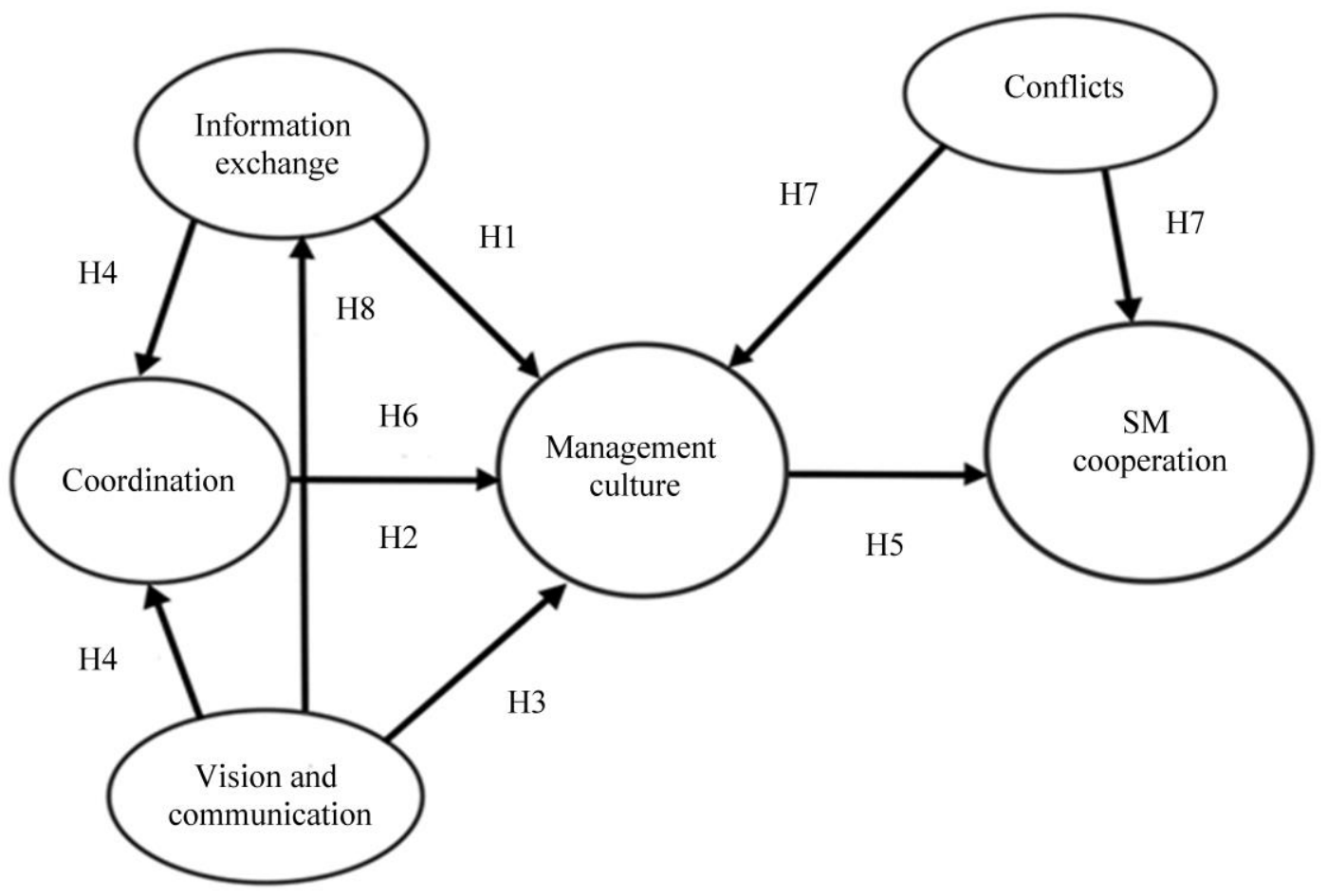

Figure 2: Research modell [27] 


\subsection{Exploring of factors affecting the cooperation between sales and marketing in PMC and NPMC}

During the investigation of PMC and NPMC manufacturing companies my research attempts to find answers to the following research questions:

- How does information exchange affect SM cooperation in PMC and NPMC?

- How does coordination (common meetings, training sessions, goals and clearly defined responsibilities) between SM affect SM cooperation in PMC and NPMC?

- How does the company vision and its communication affect SM cooperation in PMC and NPMC?

- How does management culture (information exchange, coordination, vision) affect SM cooperation in PMC and NPMC?

- How do conflicts between SM affect SM cooperation in PMC and NPMC?

- How does a shared perception of the ideal customer affect SM cooperation in PMC and NPMC?

(Hetényi et al., 2019)

\begin{tabular}{|c|c|}
\hline Vision (V1) & The company management has a clear vision for the future \\
\hline $\begin{array}{l}\text { Communication of the vision } \\
\text { (V2) }\end{array}$ & The management communicates the company vision efficiently \\
\hline $\begin{array}{c}\text { SM communication } \\
\text { (V3) }\end{array}$ & The communication between SM in general is very good \\
\hline $\begin{array}{c}\text { Information exchange } \\
\text { (V4) }\end{array}$ & Information exchange between SM departments is optimal \\
\hline $\begin{array}{c}\text { Common IT, CRM } \\
\text { (V5) }\end{array}$ & The inter-divisional IT platform (CRM system) greatly helps information exchange \\
\hline $\begin{array}{c}\text { Common training sessions } \\
\text { (V6) }\end{array}$ & SM staff members have regular common training sessions \\
\hline $\begin{array}{c}\text { Common goals for SM } \\
\text { (V7) }\end{array}$ & SM departments share a common goal they both work for \\
\hline $\begin{array}{c}\text { Common Meetings for SM } \\
\text { (V8) }\end{array}$ & There are regular common meetings for SM staffs \\
\hline $\begin{array}{c}\text { Roles \& responsibilities } \\
\text { (V9) }\end{array}$ & SM have clearly defined areas of responsibilities \\
\hline $\begin{array}{l}\text { Ideal customer } \\
\text { (V10) }\end{array}$ & SM share a mutual perception of the ideal customer \\
\hline
\end{tabular}




\begin{tabular}{|c|c|}
\hline $\begin{array}{c}\text { Conflicts } \\
\text { (V11) }\end{array}$ & Conflict negatively affect SM cooperation \\
\hline
\end{tabular}

Table 1: Variables used for PLS path modelling [25]

Table 1 contains (see table 1 ) the 11 statements that respondents had to rate on a 5 -point Likert scale ( $1=$ totally disagree, $5=$ totally agree). The answers to these statements provided the basis of PLS modelling.

\subsection{Using Voyant Tools to investigate the sales-marketing interface}

Answers to three open-ended questions were visualised in various ways using the online toolset of Voyant Tools. Respondents had to answer the following three questions:

- Please describe your daily tasks in a few sentences. is i-p?

- What are the tasks of the other (sales or marketing) department? iscpeps

- How is sales-marketing cooperation managed in your company?

iscepir(Hetényi et al., 2019)

\section{Data and methodology}

\subsection{Sampling procedure}

Six international (Austrian, Hungarian, German, English) companies were involved in the research. As the present study is exploratory in nature, a sample of convenience was considered appropriate. Online self-reported questionnaire was used to gather information. The original Hungarian questionnaire was translated into English and German to make it easier for the respondents of different nationalities to interpret the questions. The questionnaire included both open-ended and closed-ended questions. Statistical analysis of the input data was performed using PLS-PM, and quantitative analysis was performed using Voyant Tools (Hetényi et al., 2019).

\subsection{Methods}

In exploring nationality differences questions in the questionnaire were grouped in the following blocks: information exchange, coordination, vision and communication, conflicts, cooperation. The model also includes a superblock called management culture. This block included information exchange, coordination and vision and communication. The reason behind the creation of the superblock was the fact that I wanted to examine the effects of coordination, information exchange and vision on the salesmarketing cooperation as a combined set of factors as well, rather than just as individual factors. Respondents were asked to rate the 12 items on a scale of 1 to 5 to reflect their perception of the extent to which the individual factors are present in the subject company. The 5-point Likert type scale, a type of psychometric response scale in which responders specify their level of agreement to a statement typically in five points: (1) Not At All; (2) Of Little Importance; (3) Of Average Importance; (4) Very Important; (5) Yes Completely (Hetényi et al., 2019). 
In exploring of factors affecting the cooperation between sales and marketing in PMC and NPMC questions were grouped in the following blocks: information exchange, coordination, vision and communication, conflicts, at last shared perception of ideal customer (Hetényi et al., 2019).

\subsubsection{Partial Least Squares Path Model (LVPLSM)}

I created a Latent Variable Partial Least Squares Path Model (LVPLSM) based on the blocks of questions in my questionnaire. In path modelling /LVPLSM/ (Wold, 1975; Tenenhaus et al., 2005; Rigdon, 2016) questions under the same topic are grouped into blocks, and then the paths and links between these blocks in terms of correlation and regression as well as their strength are examined. The model is exploratory, thus it is suitable for eliminating insignificant links. The path model creates a common latent variable from the observed factors (input variables) in each block (external factor model or measurement model) based on their correlations. Regression links between the latent variables are explored by the internal structural model. I applied the GoF (Goodness of Fit) indicator to measure the goodness of the model. This indicator is calculated via geometrical average as the average R2 value of the regression estimates of the average variance extracted (AVE) explained by the blocks and the internal structural model. The AVE indicator needs to be above 0.4-0.5 (Chin, 1998). In terms of R2 values, $0.02 ; 0.15$ and 0.35 are considered low, medium and high reference values, respectively (Cohen, 1988). In terms of GoF, reference values, $0.10 ; 0.25$ and 0.36 are considered as unacceptable, acceptable and good model fit, respectively (Wetzels et al., 2009). In the interpretation of latent variables, I can only include those items in the block that have a correlation coefficient of above 0.5. I applied the Fornell and Larcker criterion to measure the discrimination potential of the model (Fornell and Larcker, 1981). As per Fornell and Larcker's criterion (1981), the individual latent variables should explain more of the items in their own block than all the other latent variables. Thus, the Fornell and Larcker test shows whether or not the different blocks are sufficiently separated from one another. For the estimation of the LVPLS (Latent Variable Partial Least Squares) model I used Version 0.4.9 of the PLS-PM (Tools for Partial Least Squares Path Modeling) package of the 3.4.4. "Someone-to-lean-on" version of the R statistics software (Hetényi et al., 2019).

\subsubsection{Voyant Tools}

For limitations of space most method demonstrations are performed on the third question, as it is the main focus of the analysis. As my work contained only three questions and the number of completed questionnaires is small too, it was possible to compare the results of quantitative analysis carried out with the help of tools of Voyant and see how accurate quantitative results are. Out of the used four different text analysis tools by me this paper attempts to demonstrate the Scatter Plot Toll. This is probably the most sophisticated tool among the text analysis tools of Voyant. The analysis functions of this tool include Principle component analysis, Correspondence analysis, document similarity check and t-SNE (t-Distributed Stochastic Neighbour Embedding) analysis. t-SNE is a prize-winning method that can be applied especially well to high dimensional data sets such as qualitative textual data (Van Der Maaten \& Hinton, 2008; Van Der Maaten, 2014). Cao and Wang define the method as follows, "t-SNE tries to preserve local neighbourhood structure from high dimensional space in lowdimensional space by converting pairwise distances to pairwise joint distributions, and optimize low dimensional embeddings to match the high and low dimensional joint distributions." (Cao \& Wang, 2017: page 1.) 
There is a tuneable function of t-SNE in Voyant, the level of perplexity $(0-100)$ which largely determines, what cluster model is plotted. If the data is very dense perplexity close to 100 might be the most suitable but with lower density data lower levels of perplexity will yield the best results, that is the most accurately identified clusters. The algorithm behind perplexity examines the "local" and "global" aspects of the data set, that is, it tries to determine the number of closest neighbours of each word (data points) or expressed differently, it can be "measure of the effective number of neighbours" (Van Der Maaten \& Hinton, 2008: page 2582), (Hetényi et al., 2019).

\section{Results}

\subsection{Nationality differences}

\subsubsection{Results of the model created for Hungarian employees}

Figure 3 shows (see figure 3) a summary of all the main blocks of variables, hidden variables and related items, as well as their relationships with Hungarian employees. The model consists of two main parts. First, an external factor model that shows how closely each block is related to a single hidden variable that summarizes the block. Second, an internal structural model that carries only the relationship between hidden variables representing blocks. The two models should be evaluated together and estimated iteratively.

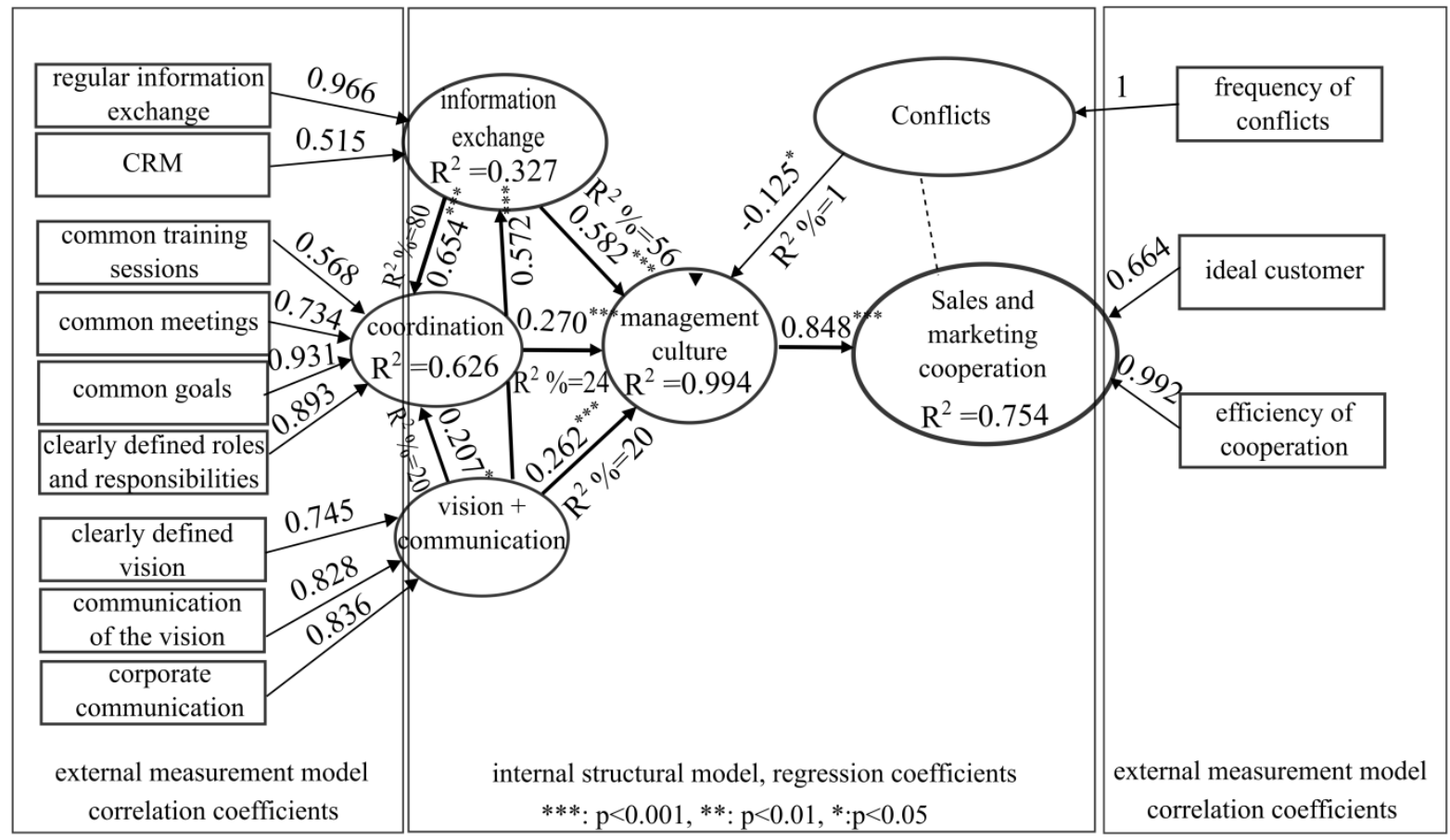

Figure 3: Estimated LVPLS model and its parameters for Hungarian employees [27]

Ovals indicate hidden variables (blocks) and squares indicate measured variables. The external measurement model (factor model) contains correlation coefficients, while the internal structural model contains regression coefficients. I created a superblock for Hungarian employees, where I inserted the vision, coordination and information exchange of hidden variables into a superblock called 
management culture. The model does not include a superblock in the foreign sample, as it did not have a significant effect on coordination, so I linked each element of the management culture separately to the collaboration. For each block, I created a hidden variable that aggregates all the elements of the block as an index. The reliability of the blocks was tested with the Dillion Goldstein RHO index. AVE: the average relative standard deviation of the elements in the sentence by the hidden variable. R2: the explained variance ratio for the regression of the latent variable.

It is evident from table 2 (see table 2) that each latent variable explains at least an average of $50 \%$ of the deviation of the items linked to it and the model does not conflict the Fornell and Larcker criterion (Hetényi et al., 2019).

\begin{tabular}{ccccccccc}
\hline Latent variable & $R^{2}$ & RHO & AVE & 1 & 2 & 3 & 4 & 5 \\
\hline $\begin{array}{c}\text { Vision (1) } \\
\text { Coordination (2) }\end{array}$ & 0.626 & 0.892 & 0.632 & 0.582 & 0.795 & $<0.001$ & 0.485 & $<0.000$ \\
$\begin{array}{c}\text { Information exchange } \\
\text { (3) }\end{array}$ & 0.327 & 0.779 & 0.599 & 0.572 & 0.773 & 0.774 & $<0.001$ & $<0.001$ \\
Conflicts (4) & n.a. & n.a. & n.a. & -0.114 & -0.082 & -0.402 & n.a & 0.005 \\
\hline Cooperation (5) & 0.754 & 0.878 & 0.713 & 0.566 & 0.846 & 0.822 & -0.322 & 0.844 \\
\hline
\end{tabular}

n.a= no data, cannot be calculated

Table 2: Key descriptive statistics of the LVPLS model for Hungarian employees [27]

The proportion of variance explained in the two regression models by the coefficient of determination or R squared is outstanding. With regard to the 'management culture' superblock, the GoF of the internal structural model was 0.675 , the GoF value of the external model was 0.610 and the entire model has a GoF of 0.642, which shows an excellent fit. Assessment of the hypotheses for Hungarian employees is as follows:

- Information exchange (H1), coordination (H2), a clear corporate vision (H3), management culture (H5) have a positive effect on the relationship of the two departments: the regression coefficients are significant. The results show that a clearly communicated and implemented corporate vision and regular information exchange (H4) have a positive effect on the coordination of the SM departments. Information exchange explains $80 \%$ of the variance of coordination, whereas vision and communication made up $20 \%$, i.e. the two factors have a different effect on coordination.

- Model estimates suggest that information exchange (H6) is the most important factor of corporate culture explaining $56 \%$ of variance, followed by coordination that affects cooperation through management culture and explains $24 \%$ of variance.

- The regression coefficient of conflicts proved significant, thus based on these results H7 is confirmed, conflicts have a negative effect on the cooperation of the two departments.

- The regression coefficient of a clearly communicated and implemented corporate vision is significant, so based on these results H8 is confirmed, a clearly communicated and implemented corporate vision boosts information exchange between SM (Hetényi et al., 2019).

\subsubsection{Results of the model created for foreign employees}

Table 3 shows (see table 3 ) that each latent variable explains at least an average of $50 \%$ of the deviation of the items linked to it (Hetényi et al., 2019). 


\begin{tabular}{ccccccccc}
\hline Latent variable & $R^{2}$ & $R H O$ & $A V E$ & 1 & 2 & 3 & 4 & 5 \\
\hline Vision (1) & $n . a$ & 0.871 & 0.432 & 0.657 & 0.082 & 0.237 & 0.447 & 0.875 \\
Coordination (2) & 0.491 & 0.764 & 0.287 & 0.334 & 0.536 & 0.006 & 0.014 & 0.004 \\
$\begin{array}{c}\text { Information exchange } \\
\text { (3) }\end{array}$ & 0.499 & 0.766 & 0.611 & -0.231 & 0.506 & 0.782 & $<0.001$ & 0.024 \\
Conflicts (4) & n.a. & n.a. & n.a. & 0.150 & -0.457 & -0.694 & $n . a$ & 0.063 \\
\hline Cooperation (5) & 0.333 & 0.812 & 0.408 & -0.031 & 0.527 & 0.425 & -0.356 & 0.639 \\
\hline
\end{tabular}

Table 3: Key descriptive statistics of the LVPLS model for foreign employees [27]

Assessment of the hypotheses for foreign employees is as follows:

- Information exchange (H1) and corporate vision (H3) have no significant effect on the relationship of the two departments: the regression coefficients are insignificant.

- Based on these results, coordination (H2) has a positive effect on the relationship of the two departments, as the regression coefficient for coordination is significant.

- The results show that a clearly communicated and implemented corporate vision and regular information exchange (H4) have a positive effect on the coordination of the SM departments. Information exchange explains $50 \%$ of the variance of coordination, whereas vision and communication made up $32 \%$, i.e. the two factors have a different effect on coordination.

- Not all three factors (H5) have a positive effect on the cooperation between the two departments, only coordination does. Based on these results $\mathrm{H} 5$ is rejected, management culture has no significant positive effect on the cooperation of the two departments.

- Model estimates suggest coordination is the most important factor of corporate culture explaining $84 \%$ of variance, followed by information exchange explaining $24 \%$ of variance. Based on these results $\mathrm{H} 6$ is confirmed, of all aspects of management culture, coordination has the most significant role in improving cooperation.

- The regression coefficient of conflicts proved significant. Conflicts have an indirect negative effect on cooperation through information exchange and coordination. Based on these results $\mathrm{H} 7$ is partly confirmed, conflicts have an indirect negative effect on the cooperation of the two departments.

- Based on these results H8 is rejected, a clearly communicated and implemented corporate vision has no significant effect on information exchange between SM (Hetényi et al., 2019).

\subsection{Differences in PMC and NPMC}

'Cooperation between sales and marketing' was the first result variable in the model that was directly affected by the elements of management culture (information exchange, clear corporate vision, coordination). Model estimates suggest that coordination is the most important factor of corporate culture, with an effect of $44 \%$, followed by information exchange that affects cooperation through management culture at $38 \%$. The regression coefficient of management culture is 0.777 with regards to cooperation. Within management culture, a significant regression parameter was estimated for 
information exchange, coordination and clear corporate vision. The regression coefficient of conflicts was $-0.136(t=-4.10 ; \mathrm{p}<0.001, \mathrm{SE}=0.033)$ with regards to management culture.

\begin{tabular}{ccccccccc}
\hline Latent variable & $R^{2}$ & $R H O$ & $A V E$ & 1 & 2 & 3 & 4 & 5 \\
\hline Vision (1) & c.b.c & 0.852 & 0.574 & 0.758 & $<0.001$ & 0.010 & 0.192 & 0.006 \\
Coordination (2) & 0.605 & 0.851 & 0.542 & 0.620 & 0.736 & $<0.001$ & 0.987 & $<0.000$ \\
$\begin{array}{c}\text { Information exchange } \\
\text { (3) }\end{array}$ & 0.145 & 0.732 & 0.472 & 0.383 & 0.671 & 0.650 & 0.249 & $<0.000$ \\
Conflicts (4) & c.b.c & c.b.c & n.a. & 0.200 & -0.003 & -0.178 & c.b.c & 0.238 \\
\hline Cooperation (5) & 0.619 & 0.867 & 0.660 & 0.406 & 0.735 & 0.643 & -0.182 & 0.812 \\
\hline
\end{tabular}

Table 4: Key statistics of the LVPLS model for PMC [25]

External measurement models also provide important information. Rather strong correlations were found between the most important factor 'coordination' and the items in the block. Coordination is most strongly affected by common meetings and clear roles and responsibilities. Latent variables 'vision' and 'communication' are most strongly linked to corporate communication and the definition of the vision itself. Latent variable 'sales and marketing cooperation' obviously has the strongest correlation with the efficiency of cooperation. A rather weak, non-significant correlation was found between CRM and information exchange.

In comparison, the analysis and the research model was applied to NPMC as well, however, model estimates revealed a difference as compared to the PMC model, since the key factor affecting cooperation through the management culture was not coordination but information exchange (57\%) (Hetényi et al., 2019).

\begin{tabular}{ccccccccc}
\hline Latent variable & $R 2$ & $R H O$ & $A V E$ & 1 & 2 & 3 & 4 & 5 \\
\hline Vision (1) & $c . b . c$ & 0.861 & 0.600 & 0.775 & $<0.001$ & $<0.001$ & 0.149 & $<0.001$ \\
Coordination (2) & 0.703 & 0.885 & 0.597 & 0.369 & 0.773 & $<0.001$ & 0.041 & $<0.001$ \\
$\begin{array}{c}\text { Information exchange } \\
\text { (3) }\end{array}$ & 0.367 & 0.825 & 0.678 & 0.367 & 0.684 & 0.823 & $<0.001$ & $<0.001$ \\
Conflicts (4) & c.b.c & c.b.c & c.b.c & 0.039 & 0.078 & 0.259 & c.b.c & $<0.001$ \\
\hline Cooperation (5) & 0.741 & 0.860 & 0.667 & 0.308 & 0.706 & 0.688 & 0.217 & 0.817 \\
\hline
\end{tabular}

c.b.c=cannot be calculated

Table 5: Key statistics of the LVPLS model for NPMC [25]

Correlation of conflict and information exchange was significant $(\mathrm{p}<0.01)$. The two main regressions of the model were the estimation of coordination based on information exchange and vision ( $(\mathrm{R} 2=0.703)$ and the estimation of cooperation based on the other latent variables (R2=0.741). As $\mathrm{R} 2$ values are high the explanatory power of the model can be considered high too. The regression coefficient of management culture is 0.802 with regard to cooperation. Within management culture, a significant regression parameter was estimated for both information exchange and coordination, as well as clear 
corporate vision. My results have revealed further differences with regard to clearly communicated and implemented corporate vision. This factor did not contribute to the better coordination and integration of the sales and marketing departments since it explained only $15 \%$ of the variance of coordination, whereas information exchange made up $85 \%$. Similarly to PMC, however, a clearly communicated and implemented corporate vision encourages information exchange between sales and marketing. However, this impact is much stronger in NPMC than in the pharmaceutical ones. Further significant differences were seen in the case of conflicts, which showed no significant negative effects.

The comparison of the external measurement models reveals only one significant difference between pharmaceutical and non-pharmaceutical companies. Common goals have the most important impact on coordination in non-pharmaceutical companies, whereas in the pharmaceutical company common meetings are the key factor (Hetényi et al., 2019).

\subsection{Quantitative analysis}

The tf-idf (term frequency-inverse document frequency) weighting method was used for the analysis. It is an option that can be set by the analyst besides the other two methods "raw frequencies" and "relative frequencies". It is a method that determines how important a word is to a document and is largely dependent on how often a word appears in a document. As there is only one document in my case, the algorithm divides the corpus into 10 segments and examines word frequencies in each segment. As it was noted earlier t-NSE is an award-winning method and the cluster plots that it is able to create can encourage jumping to conclusions that might not at all be sound. There are several reasons for this, for example the factors are the level of perplexity and the number of iteration (Hetényi et al., 2019)

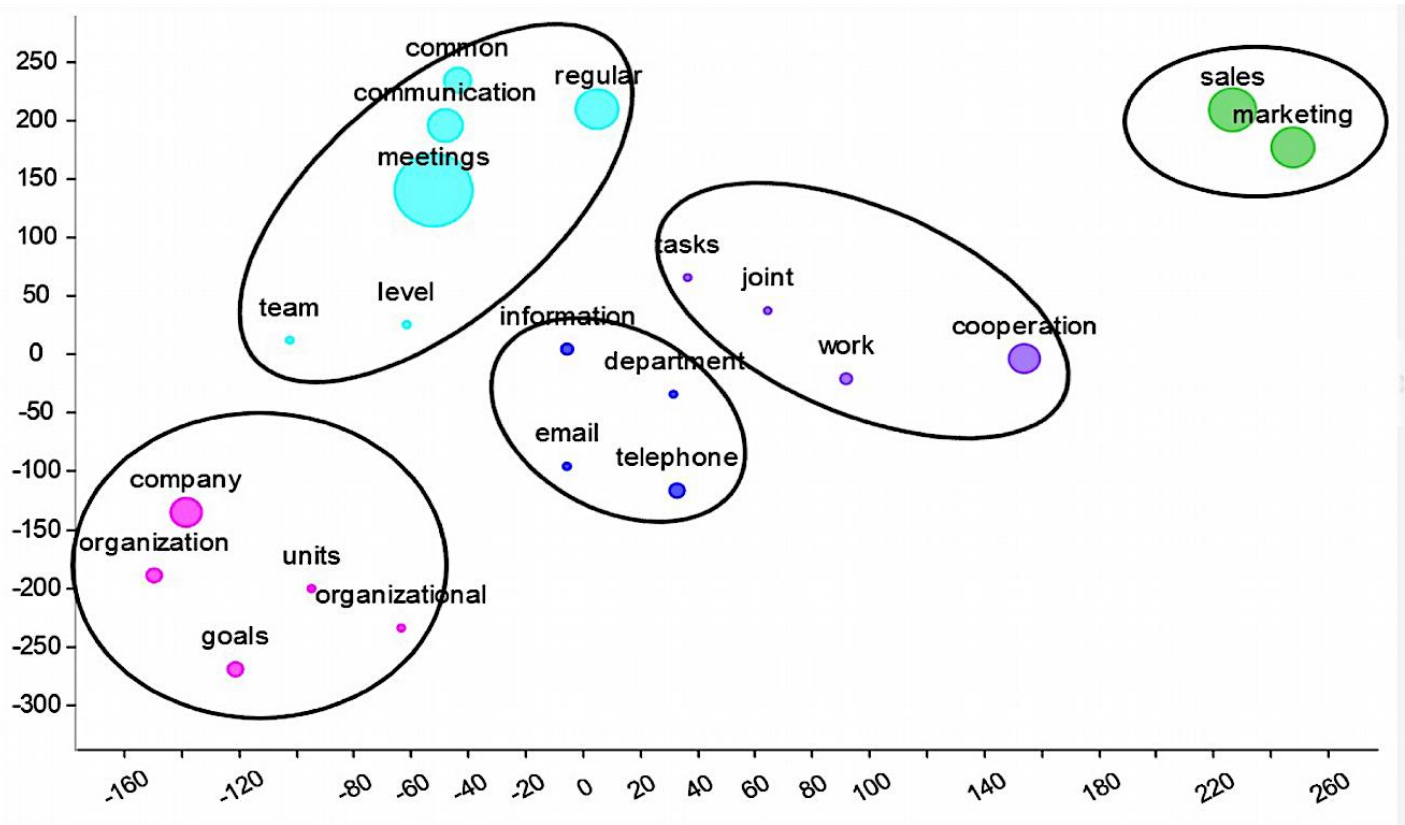

Figure 4: t-SNE generated clusters for the answers to Question 3, 900 iterations [26]

900 iterations yielded the best result with the clusters being the tightest (Figure 4). The colours reflect data points (words in this case) that belong to the same cluster, while the size of the points is proportionate to the relative frequency of words. SM seems to be strongly related, which might be 
attributable to the nature of the question. There is a clearly detectable cluster that is about communication. Regular meetings and appropriate communication in general can significantly improve cooperation (Madhani, 2016) and reduces conflict (Snyder, McKelvey \& Sutton, 2016). Communication and information sharing between SM is considered to be one of the keys to an effective management of the SMI (Biemans, Brenčič \& Malshe, 2010).

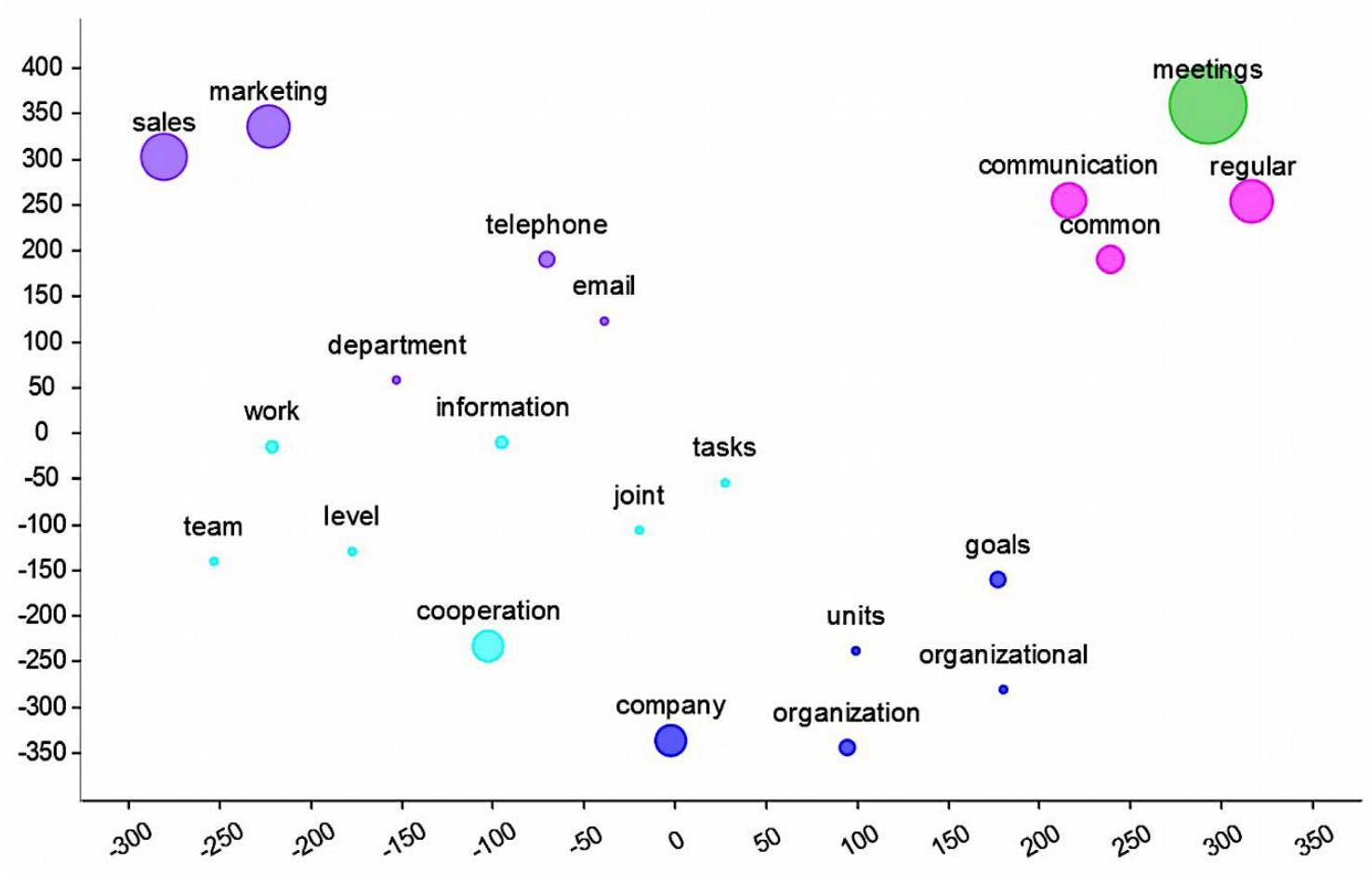

Figure 5: $t$-SNE generated clusters for the answers to Question 3, 5000 iterations [26]

In Figure 5 (see figure 5) there is a separate cluster that contains the most important information sharing methods in the two departments (telephone, email). Points marked in lilac signal the importance of joint tasks and work as well as cooperation between SM departments. It is interesting that there is a "corporate level" cluster with terms such as "company", "organisation", "goals" which highlights the significance of how corporate goals and vision can influence the efficiency of SM. It also supports earlier literature emphasizing corporate vision (Kumar, 2016; Groysberg, Lee, Price \& Cheng, 2018, Hetényi et al., 2019)

\section{Conclusion}

Based on the results, it can be said that there were differences between the nationalities in the evaluation of the selected factors influencing the relationship of SM. Hungarians considered the importance of information exchange more important than their foreign colleagues. Further research is needed to identify the exact causes of this. A possible factor may be that market capitalism has existed in Hungary for thirty years, and the strong presence of international (multinational) companies has been characteristic only for the last twenty years. This may also explain the striking difference in the importance that Hungarian and foreign SM employees attach to the common goals of the two departments, as well as the significant difference in the assessment of the importance of clearly defined roles and responsibilities. For Hungarians, the clearer the common goals become, and the clearer the 
role and responsibilities of the MS, the stronger the coordination and cooperation between the SM. Significant negative correlations between information exchange, CRM and joint meetings for foreign workers indicate that the malfunctioning of these areas is likely to cause conflict, as can be seen for Hungarian employees, where the three areas are also negatively correlated with conflicts, but to a much lesser extent. This may be explained by the previously mentioned difference between long-established market companies (Austria, Germany, England) and young people such as Hungary. Foreign employees in these societies are likely to be more accustomed to effective information exchange, IT systems, or meetings than their counterparts in their home countries.

In terms of similarities, it should be noted that both Hungarian and foreign MS staff consider joint meetings and trainings, as well as the common IT platform of the two departments, to be important factors of cooperation. The clear definition and communication of the corporate vision has a positive effect on the quality of SM cooperation, thus having a direct impact on the quality of coordination of both Hungarian and foreign staff.

Results suggest that in NPMC improving the quality of information exchange is likely to enhance SM cooperation considerably more than in PMC. The putative explanation for this difference is attributable to the impact of IT (e.g., CRM). PMC is subject to various GxP regulations (Wingate, 2016) that are not applicable to NPMC. It seems that in PMC the improvement of coordination is more likely to result in improved SM cooperation than in NPMC. Clearly defined roles and responsibilities are equally important elements of good coordination in both types of companies, however, in PMC it is common meetings, while in NPMC it is common goals that have the strongest correlation with coordination. The "marketing and sales collaboration" factor is significantly influenced by elements of the management culture, which draws attention to the importance of examining the various factors that affect each corporate function in the future.

The managerial implications of the results may be multifaceted, however, although the sample was limited, the results seem to support previous research that described a close link between the efficient operation of multinational companies and the knowledge that cultural differences, such as how nationality factors can influence corporate processes.

These Voyant tools can be valuable for professional and scientific purposes for a variety of reasons. In a scientific environment where time constraints are not as urgent as in the business world, they can serve as a tool for preliminary analysis before more conservative and traditional methods of qualitative data analysis, such as guided text analysis or a well-established theoretical technique. In a business environment where time efficiency directly affects cost efficiency, these tools are invaluable in saving time and energy. The t-SNE tool provides the highest level of sophistication and the deepest analytical capabilities, exploring how groups of terms relate to each other.

In an exploratory way, this work sought to examine the extent to which Hungarian and foreign employees of the SM departments of international companies differ in the assessment of important factors determining the quality of cooperation between SM. Furthermore, how the selected factors affect the cooperation of SM in PMC and NPMC, highlighting the differences and similarities between these two types of manufacturing companies. 
Future use of the PLS-PM complex modeling technique presented in this paper to help optimize the SM interface may help to uncover additional underlying mechanisms that cannot be covered from descriptive statistics or correlation tables.

The use of qualitative methods is playing an increasingly important role, especially in areas such as interface. One such interface challenge is the SM interface, which this article presents as an example to illustrate the possibilities offered by Voyant Tools. In the future, Voyant Tools may also serve as a useful and valuable complementary technique, as the incorporation of quantitative analysis techniques into the analysis of qualitative data may provide a more solid basis for constructing research conclusions. Voyant-Tools offers an impressive series for displaying the results of qualitatively analyzed qualitative data. However, these quantitative methods can be invaluable tools for preliminary analysis and hypothesis adjustment. As there is virtually little previous literature on the use of quantitative data visualization techniques in marketing research, particularly SMI analysis, the use of Voyant Tools and other quantitative data analysis and visualization software to manage qualitative data is definitely a worthwhile area for further research.

With the following article, I wanted to summarize the new research methods of the cooperation of marketing and sales for the Hungarian literature, which can provide further evaluation opportunities in the same and other research topics.

\section{References}

[1] Ahsan, A. K. (2018) 'Factors affecting inter-organisational coordination: a case of policy implementation in rural Bangladesh', Development in Practice, 28(8), 1083-1093.

[2] Al-jawazneh, B. E. (2015) 'Conflict handling Styles and Employees' Commitment at the Pharmaceutical Companies in Jordan', International Journal of Business and Management, 10(3), 141.

[3] Bakacsi, Gy. (2001) 'Szervezeti magatartás és vezetés'. Közgazdasági és Jogi Kiadó, Budapest, ISBN $9632244966,1-353$.

[4] Bargeron, L., Lehn, K., Smith, J. (2015) 'Employee-management trust and M\&A activity', Journal of Corporate Finance, 389-406. ISSN 0929-1199.

[5] Bauer, R. (2000) 'Vertriebsorganisation'. In: R. Reichwald \& H.J. Bullinger (Eds.), Vertriebsmanagement: Organisation - Technologieeinsatz - Personal (35-83). Stuttgart: SchäfferPoeschl.

[6] Biemans, W. G., Brenčič, M. M., \& Malshe, A. (2010) 'Marketing-sales interface configurations in B2B firms', Industrial Marketing Management, 39(2), 183-194.

[7] Birkinshaw, J., Zimmermann, A., \& Raisch, S. (2016) 'How do firms adapt to discontinuous change? Bridging the dynamic capabilities and ambidexterity perspectives', California Management Review, 58(4), 36-58. 
[8] Bititci, U. S., Martinez, V., Albores, P., Parung, J. (2004) 'Creating and Managing Value in Collaborative Networks', International Journal of Physical Distribution and Logistics Management, 34(3-4), 251-268.

[9] Blomqvist, K., Hurmelinna, P., Seppanen, R. (2005) 'Playing the co-operation game right-balancing trust and contracting', Technovation, 25(5), 497-504.

[10] Cao, Y., \& Wang, L. (2017) 'Automatic selection of t-SNE Perplexity'. arXiv preprint arXiv:1708.03229.

[11] Cespedes, F. V. (1993) 'Coordinating Sales and Marketing in Consumer Goods Firms', Journal of Consumer Marketing, 10(2), 37-55.

[12] Cespedes, F. V. (1994) 'Industrial Marketing: Managing New Requirements', Sloan Management Review, 35(3), 45-60.

[13] Cornaggia, K. J., Krishnan, G. V., Wang, C. (2017) 'Managerial ability and credit ratings', Contemporary Accounting Research, 2094-2122. ISSN 0823-9150.

[14] Dalla Pozza, I., Goetz, O., \& Sahut, J. M. (2018) 'Implementation effects in the relationship between CRM and its performance', Journal of Business Research, 89, 391-403.

[15] Dawes, P. L., Massey, G. R. (2001) 'A Model and Empirical Test of Marketings Cross - Functional Relationship with Sales', Working Paper, ISBM Report 8-2001, The Pennsylvania State University Park.

[16] Dewsnap, B., \& Jobber, D. (2002) 'A social psychological model of relations between marketing and sales', European Journal of Marketing, 36(7/8), 874-894.

[17] Erturk, E., \& He, S. (2018) 'Study on A High-integrated Cloud-Based Customer Relationship Management System'. arXiv preprint arXiv:1812.09005.

[18] Ferdous, A. S. (2008) 'Integrated internal marketing communication (IIMC)', The Marketing Review, 8(3), 223-235.

[19] Gelei, A. (2005) 'Munkavégzési rendszerek'. In: Bakacsi, Gy., Bokor, A., Gelei, A., Kováts, K., Takács, S. (2005): Stratégiai Emberi Erőforrás Menedzsment. Kolozsvár, Scientia.

[20] Genis, J. \& Wallis, T. (2005) 'Work as a central life interest for legal professionals', Journal of Industrial Psychology, 31(1), 65-70.

[21] Groysberg, B., Lee, J., Price, J., \& Cheng, J. (2018) 'The leader's guide to corporate culture', Harvard Business Review, 96(1), 44-52.

[22] Guenzi, P., \& Troilo, G. (2007) 'The joint contribution of marketing and sales to the creation of superior customer value', Journal of Business Research, 60(2), 98-107.

[23] Haase, K. (2006) 'Koordination von Marketing und Vertrieb'. Wiesbaden: Deutscher UniversitätsVerlag.

[24] Hackman, J. R., \& Oldham, G. R. (1976) 'Motivation through the design of work: Test of a theory', Organizational Behavior and Human Performance, 16, 250-279. 
[25] Hetényi G., Lengyel A., Szilasi M. (2019) 'PLS Modelling of factors affecting the cooperation between sales and marketing in pharmaceutical and non-pharmaceutical manufacturing firms', Market-Tržište, išrepi]31 (2), 227-247.

[26] Hetényi G., Lengyel A., Szilasi M. (2019) 'Quantitative Analysis of Qualitative Data: Using Voyant Tools to Investigate the Sales-Marketing Interface', Journal of Industrial Engineering and Management, 12 (3), 73-89.

[27] Hetényi G., Lengyel A., Szilasi M., Szűcs E. (2019) 'Nationality differences affecting the cooperation of SM: PLS modelling of data from six international companies', Selye e-studies, 10 (2), 46-63.

[28] Homburg C., Jensen O., \& Krohmer H. (2008) 'Configurations of Marketing and Sales: A Taxonomy', Journal of Marketing, 72 (2), 133-154.

[29] Homburg, C., \& Jensen. O. (2007) 'The Tought Words of Marketing and Sales - Which Differences Make a Difference?', Journal of Marketing, 71(3), 124-142.

[30] Homburg, C., Alavi, S., Rajab, T., \& Wieseke, J. (2017) 'The contingent roles of R\&D-sales versus R\&D-marketing cooperation in new-product development of business-to-business firms', International Journal of Research in Marketing, 34(1), 212-230. ISSN 0167-8116.

[31] Huang, J. C., Wu, T. J., Wen, H. M., Hsin-Fei, W., \& Hairui, J. (2017) 'Research into the influence of internal interdepartmental integration on service innovation and customer loyalty'. In AIP Conference Proceedings (1836(1), 020006). AIP Publishing.

[32] Järvinen, J., \& Taiminen, H. (2016) 'Harnessing marketing automation for B2B content marketing', Industrial Marketing Management, 54, 164-175.

[33] Jo Hatch, M., \& Schultz, M. (2003) 'Bringing the corporation into corporate branding', European Journal of Marketing, 37(7/8), 1041-1064.

[34] Johnson, J. S., Matthes, J. M., \& Friend, S. B. (2017) 'Interfacing and customer-facing: Sales and marketing selling centers', Industrial Marketing Management. http://dx.doi.org/10.1016/j.indmarman.2017.08.011.

[35] Kahn, K. B. (1996) 'Interdepartmental integration: a definition with implications for product development performance', Journal of product innovation management, 13(2), 137-151.

[36] Keszey, T., \& Biemans, W. (2016) 'Sales-marketing encroachment effects on innovation', Journal of Business Research, 69(9), 3698-3706. ISSN 0148-2963.

[37] Kirsch, A., Stoyke, T. S. (2011) 'Erfolgsfaktoren für eine produktive Zusammenarbeit zwischen Marketing und Vertrieb: Bestandsaufnahme, Trends, Lösungsmöglichkeiten und Grenzen der Einflussnahme', Wismarer Diskussionspapiere, No. 06/2011. Wismar: Hochschule Wismar, Fakultät für Wirtschaftswissenschaften.

[38] Klumpp, T. (2000) 'Zusammenarbeit von Marketing und Verkauf'. St. Gallen: Thexis.

[39] Kotler, P., Rackham, N., \& Krishnaswamy, S. (2006) 'Ending the war between sales and marketing', Harvard business review, 84(7/8), 68. 
[40] Krafft, M. (1995) 'Aussendienstentlohnung im Licht der Neuen Institutionenlehre'. Wiesbaden: Gabler.

[41] Krush, M. T., Malshe, A., Al-Khatib, J., Al-Jomaih, K., \& Katoua, H. (2015) 'Value Creation within the Sales-Marketing Interface: The Varied Approaches to Integration', Journal of Selling, 14(2), 6-19.

[42] Kumar, D. (2016) 'Enterprise growth strategy: vision, planning and execution'. London: Routledge. ISBN: 978-0-566-09198-8.

[43] Lamasheva, Y. (2004) 'International Cooperation and Competitiveness on a Regional Level: Theoretical overview', Social Culture Research, 3(29), 73-94. ISSN 1479-7585.

[44] Le Meunier-FitzHugh, K., \& Le Meunier-FitzHugh, L. C. (2016) 'Sales and Marketing, and Customer Relationships: A Structured Abstract'. In: L. Petruzzellis, \& R.S. Winer (Eds.), Rediscovering the Essentiality of Marketing (779-780). Cham: Springer.

[45] Le Meunier-FitzHugh, K., \& Piercy, N. (2007) 'Does Collaboration Between Sales and Marketing Affect Business Perforamance?', Journal of Personal Selling and Sales Management, 27(3), 201-220.

[46] Le Meunier-FitzHugh, K., \& Piercy, N. F. (2007) 'Exploring collaboration between sales and marketing', European Journal of Marketing, 41(7/8), 939-955.

[47] Madhani, P. M. (2015) 'Sales and marketing: integration', SCMS Journal of Indian Management, $12(2), 17-28$.

[48] Madhani, P. M. (2016) 'Competitiveness and sustaining performance: integrating sales and marketing', SCMS Journal of Indian Management, 13(1), 19-36.

[49] Madhani, P. M. (2016) 'Sales and marketing integration: Enhancing competitive advantages', The IUP Journal of Business Strategy, 13(4), 50-77.

[50] Malshe, A., Friend, S. B., Al-Khatib, J., Al-Habib, M. I., \& Al-Torkistani, H. M. (2017) 'Strategic and operational alignment of sales-marketing interfaces: Dual paths within an SME configuration', Industrial Marketing Management, 66, 145-158. ISSN 00198501.

[51] Malshe, A., Johnson, J. S., \& Viio, P. (2017a) 'Understanding the sales-marketing interface dysfunction experience in business-to-business firms: A matter of perspective', Industrial Marketing Management, 63, 145-157. ISSN 00198501.

[52] Martinez, L. A. M., \& Hurtado, S. R. F. (2018) 'Internal Communication Issues in the Firms: Does It Affect the Productivity', Review of European Studies, 10(2), 1-13.

[53] Matsuo, M. (2006) 'Customer orientation, conflict, and innovativeness in Japanese sales departments', Journal of Business Research, 59(2), 242-250.

[54] Matthyssens, P., \& Johnston, W. J. (2006)' Marketing and sales: optimization of a neglected relationship', Journal of Business \& Industrial Marketing, 21(6), 338-345.

[55] Mayer, J., \& Nyhuis, P. (2016) 'Cybernetic Approach for Interdepartmental Cause-effect Relationship Modelling', Universal Journal of Management, 4(9): 488-499. 
[56] Miles, R. E., Miles, G., Snow, C. C. (2005) 'Collaborative Entrepreneurship: How Groups of Network Firms Use Continuous Innovation to Create Economic Wealth'. Stanford: Stanford University Press. ISBN 9780804748018.

[57] Moncrief, W. C. (2017) 'Are sales as we know it dying... or merely transforming?', Journal of Personal Selling \& Sales Management, 37(4), 271-279.

[58] Morgan, N. A., \& Slotegraaf, R. J. (2012) 'Marketing capabilities for B2B Firms', Handbook of Business-to-Business Marketing, 90-108.

[59] Omar, R., Ramayah, T., Lo, M. C., Sang, T. Y., \& Siron, R. (2010) 'Information sharing, information quality and usage of information technology (IT) tools in Malaysian organizations', African Journal of Business Management, 4(12), 2486-2499.

[60] Piercy, N. F. (2002) 'Market-Led Strategic Change'. Butterworth Heinemann, Amsterdam et al. 252-258.

[61] Pinto, M. B., Pinto, J. K., Prescott, J. E. (1993) 'Antecedents and Consequencies of Project Team Cross-functional Cooperation', Management Science, 39, 1281-1297.

[62] Pohludka, M., \& Štverková, H. (2019) 'The Best Practice of CRM Implementation for Small-and Medium-Sized Enterprises', Administrative Sciences, 9(1), 22.

[63] Raab, W. (2010) 'A nemzetközi gazdasági együttmúködés lehetőségei és korlátai a két világháború között’. V. Rab \& Á. Deák (Eds.), Együttmúködés és versengés (pp. 155-161). Budapest: Gondolat Kiadó.

[64] Rahim, M. A. (2017) 'Managing conflict in organizations'. New York, NY: Routledge. ISBN 9780203786482.

[65] Razmerita, L., Kirchner, K., Nielsen, P. (2016) 'What factors influence knowledge sharing in organizations? A social dilemma perspective of social media communication', Journal of Knowledge Management, 1225-1246. ISSN 1367-3270.

[66] Roberson, L. (1990) 'Functions of work meanings in organizations: work meanings and work motivation', In Brief, A. P. \& Nord, W. R. (Eds), Meanings of occupational work: A collection of essays. Lexington, MA: Lexington Books.

[67] Rosenauer, D., Homan, A. C., Horstmeier, C. A., Voelpel, S. C. (2016) 'Managing nationality diversity: the interactive effect of leaders' cultural intelligence and task interdependence', British Journal of Management, 628-645. ISSN 1045-3172.

[68] Rouziès, D., Anderson, E., Kohli, A. K., Michaels, R. E., Weitz, B. A., \& Zoltners. A. A. (2005) 'Sales and marketing integration - A proposed framework', Journal of Personal Selling and Sales Management, 25(2), 113-122.

[69] Salancik, G. R. \& Pfeffer, J. (1978) 'A social information processing approach to job attitudes and task design', Administrative Science Quarterly, 23, 224-253.

[70] Shamir, B. (1991) 'Meaning, self and motivation in organizations', Organization Studies, 12, 405424. 
[71] Sleep, S., Lam, S. K., \& Hulland, J. (2018) 'The sales-marketing integration gap: a social identity approach', Journal of Personal Selling \& Sales Management, 38(4), 371-390.

[72] Smith, E. R., Mackie, D. M. (2004) 'Szociálpszichológia’. Osiris kiadó, Budapest, 1-968.

[73] Snow, C. C. (2015) 'Organizing in the age of competition, cooperation, and collaboration', Journal of leadership \& organizational studies, 433-442. ISSN 15480518.

[74] Snyder, K., McKelvey, S., \& Sutton, W. (2016) 'All together now? Exploring sales and marketing integration. Sport, Business and Management', An International Journal, 6(1), 2-18.

[75] Song, M. X., Xie, J. \& Dryer, B. (2000) 'Antecedents and Consequences of Marketing Managers' Conflict-Handling Behaviors', Journal of Marketing, 64(1), 50-66.

[76] Thornton, G. S. (2019) 'Internal Communications Flourishes at the Grassroots: The Growing Importance of Managers in Employee Engagement'. Strategic Employee Communication (107120). Cham: Palgrave Macmillan.

[77] Tomek, G., Vávrová, V., Červenka, P., Naščáková, J., \& Tomčíková, M. (2016) 'Corporate vision from management development in the globalization context'. M. Majerník, N. Daneshjo, \& M. Bosák (Eds.), Production Management and Engineering Sciences (297-303). London: ROUTLEDGE in association with GSE Research.

[78] Vahs, D. (2012) 'Organisation - Ein Lehr- und Managementbuch'. Stuttgart.

[79] Van Der Maaten, L. (2014) 'Accelerating t-SNE using tree-based algorithms', The Journal of Machine Learning Research, 15(1), 3221-3245.

[80] Van Der Maaten, L., \& Hinton, G. (2008) 'Visualizing high-dimensional data using t-sne', Journal of Machine Learning Research, 9, 26.

[81] Wang, X. H., Fang, Y., Qureshi, I., \& Janssen, O. (2015) 'Understanding employee innovative behavior: Integrating the social network and leader-member exchange perspectives', Journal of organizational behavior, 36(3), 403-420.

[82] Weber, J. \& Schäffer, U. (2000) 'Balanced Score Card \& Controlling. Implementierung - Nutzen für Manager und Controller - Erfahrungen in deutschen Unternehmen’. Wiesbaden.

[83] West, D. C., Ford, J., Ibrahim, E. (2015) 'Strategic marketing: creating competitive advantage', New York: Oxford University Press. ISBN: 9780199684090.

[84] Wierum, D. (2001) 'Zusammenarbeit zwischen Personal - und F\&E Bereich - Analyse und Gestaltungsmöglichkeiten auf der Basis des Schnittstellenmanagements’. Wiesbaden: Gabler.

[85] Wolfrum, B. (1994) 'Schnittstellenprobleme zwischen F\&E und Marketing im Innovationsmanagement', Das Wirtschaftsstudium, 23(12), 1016-1022.

[86] Wunderer, R. (1985) 'Zusammenarbeit zwischen Organisationseinheiten - Zur Analyse von Grundmustern lateraler Kooperationsbeziehungen'. Integriertes Management: Bausteine des systemorientierten Managements, Bern-Stuttgart. 